\title{
THE
}

1993

\section{Synthesis of Aluminum Hydroxide Nanoparticles in Spontaneously Generated Vesicles}

Iskandar I. Yaacob

Suhas Bhandarkar

Arijit Bose

University of Rhode Island, bosea@uri.edu

Follow this and additional works at: https://digitalcommons.uri.edu/che_facpubs

Part of the Chemical Engineering Commons

Terms of Use

All rights reserved under copyright.

\section{Citation/Publisher Attribution}

Yaacob, I. I., Bhandarkar, A., \& Bose, A. (1993). Synthesis of Aluminum Hydroxide Nanoparticles in Spontaneously Generated Vesicles. Journal of Materials Research, 8(3), 573-577. doi: 10.1557/ JMR.1993.0573

Available at http://dx.doi.org/10.1557/JMR.1993.0573

This Article is brought to you for free and open access by the Chemical Engineering at DigitalCommons@URI. It has been accepted for inclusion in Chemical Engineering Faculty Publications by an authorized administrator of DigitalCommons@URI.For more information, please contact digitalcommons-group@uri.edu. 


\title{
Synthesis of aluminum hydroxide nanoparticles in spontaneously generated vesicles
}

\author{
Iskandar I. Yaacob \\ Department of Chemical Engineering, University of Rhode Island, Kingston, Rhode Island 02881-0805
}

Suhas Bhandarkar

AT\&T Bell Laboratories, 600 Mountain Avenue, Murray Hill, New Jersey 07974

Arijit Bose ${ }^{\text {a) }}$

Department of Chemical Engineering, University of Rhode Island, Kingston, Rhode Island 02881-0805

Unilamellar vesicles, formed spontaneously by mixing single-tailed cationic (cetyl trimethyl ammonium tosylate, CTAT) and anionic aqueous solutions of (sodium dodecyl benzene sulfonate, SDBS) surfactants have been used as reactors for the aqueous phase precipitation of nanometer sized particles within their inner cores. $\mathrm{AlCl}_{3}$ solution was encapsulated within these vesicles, aluminum ions were replaced with sodium ions in the extravesicular phase, and sodium hydroxide was then added to the extravesicular region. Hydroxyl ions penetrate through the vesicle walls and react with the available aluminum in the intravesicular region to form the product. The morphology and sizes of these particles were examined by transmission electron microscopy, while their phase and crystalline nature were probed by electron and $\mathrm{x}$-ray diffraction. The product particles were nanometer-sized with near spherical morphology. Good control of particle size was achieved by varying the initial concentration of electrolyte. Single particle electron diffraction revealed a symmetric pair of spots, indicating that the particles were either single crystals or polycrystalline with a low number of grain boundaries or defects. Although wide area electron diffraction showed that the product was $\delta-\mathrm{Al}_{2} \mathrm{O}_{3}$, powder x-ray diffraction revealed that these particles were, in fact, $\mathrm{Al}(\mathrm{OH})_{3}$. It is likely that heating of these nanoparticles by the high energy electron beam in a high vacuum environment causes a phase transformation, resulting in the difference between the electron and $\mathrm{x}$-ray diffraction results. These results represent the first demonstration of precipitation within vesicles produced spontaneously by mixing appropriate ratios of inexpensive single-tailed surfactants, and may potentially make intravesicular precipitation a commercially viable route for making nanometer-sized particles.

\section{INTRODUCTION}

Nanometer-sized ceramic particles can serve as useful green material for sintering of ceramic parts, ${ }^{1}$ as seed material for the production of larger particles, ${ }^{2}$ as catalysts, ${ }^{3}$ and as magnetic ${ }^{4,5}$ and piezoelectric materials. Some advantages related to their size are the possibility of low temperature ductility because of diffusional creep along grain boundaries, ${ }^{6}$ lower sintering temperature or time during the consolidation of ceramic parts, ${ }^{7}$ and anomalous behavior known as "quantum size effects". It is well known, for example, that the band gaps displayed by semiconducting nanoparticles differ significantly from those in bulk material, considerably expanding their range of uses. For these reasons, there is a significant drive in the ceramic industry to produce narrowly dispersed ultrafine particles.

a) Author to whom correspondence should be addressed.
Particles in this size range can be produced by a variety of techniques including aerosol reactions, ${ }^{8}$ evaporation and condensation on cold fingers, ${ }^{9}$ mechanical crushing of powders, or by aqueous phase colloidal processing techniques such as precipitation using microemulsions and intravesicular precipitation. Indeed, Mann and Williams, ${ }^{3}$ Mann and Hannington, ${ }^{4}$ Bhandarkar and Bose, ${ }^{10,11}$ and Liu et al. ${ }^{12}$ have demonstrated the formation of nanometer-sized ceramic particles by precipitation in single compartment vesicles. In that technique, an inorganic salt is encapsulated within the inner core of the vesicles by sonicating phospholipid molecules in the aqueous salt solution. The extravesicular cations are replaced by passing the solution through an ion exchange column. Hydroxyl ions are then added to the extravesicular regions. The slow permeation of the $\mathrm{OH}^{-}$ions into the inner core of the vesicles provides low internal supersaturation and causes nucleation on the "membrane" wall. The nucleus then grows into a single crystal until all the intravesicular cations are 
exhausted or the reaction is terminated deliberately. The principle behind the formation of nanoparticles within the membrane constrained cavities can be understood as follows: if the aqueous core is assumed spherical, the expected fully dense equivalent spherical particle diameters, $d=0.1 D(N \mathrm{MW} / \rho)^{1 / 3}$, where $d$ and $D$ are the particle and vesicle internal diameters in angstroms, $N$ is the internal solution molarity, MW the molecular weight of the product, and $\rho$ the product density in $\mathrm{gm} / \mathrm{cc}$. Particle sizes, therefore, can be controlled by varying the solution concentration and vesicle sizes.

Kaler et al. ${ }^{13}$ have demonstrated that the simultaneous addition of the appropriate proportions of singletailed cationic (cetyl trimethyl ammonium tosylate, CTAT) and anionic (sodium dodecyl benzene sulfonate, SDBS) surfactants to water spontaneously produces stable single compartment vesicles. This formation can be understood conceptually by recognizing that when these two surfactant solutions are mixed, the anionic and cationic surfactants will pair up and form pseudo double-tailed zwitterionic molecules. The surfactant pair is highly surface active and has the geometric feature of a smaller polar head group and larger hydrophobic region, which is necessary for vesicle formation. In this paper, we explore the ability of the spontaneously produced vesicles to serve as nanoreactors for the precipitation of ceramic particles within their inner cores. Not only is this interesting from a fundamental perspective, the success of this method would mean the elimination of the energy intensive sonication or pressure filtration steps required to form vesicles from phospholipids and reduce raw material cost dramatically. Furthermore, because these surfactants are known to be solubilized easily by the nonionic surfactant Triton X-100, this could be a straightforward way to extract the particles from their surrounding membranes. All of these factors have the potential of making intravesicular precipitation conceivable on a larger scale.

\section{EXPERIMENTAL PROCEDURE}

Single distilled water was passed through a four cartridge Millipore "Milli Q" system until its resistivity reached $18 \mathrm{M} \Omega-\mathrm{cm}$. This water was used for solution preparation and for final rinsing of glassware. Reagent grade $\mathrm{AlCl}_{3}$ and $\mathrm{NaOH}$ were obtained from Fisher Scientific. CTAT was obtained from Sigma Chemical and was 99\% pure. Technical grade SDBS was purchased from Aldrich Chemicals. These surfactants were used without further purification. Industrial grade sodium form ion exchange resin (Amberlite IR-120) and Triton X-100 were obtained from Rohm and Haas. All experiments were performed at room temperature.

A schematic of the experimental procedure used is shown in Fig. $1.8 \mathrm{mM}$ stock solutions of SDBS and

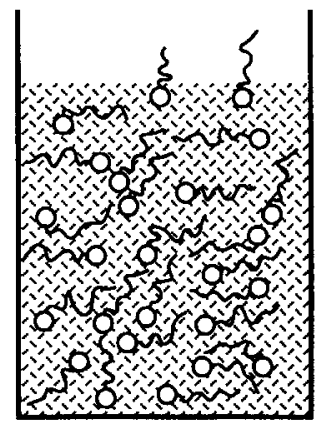

CTAT in $\mathrm{AlCl}_{3}$ solution

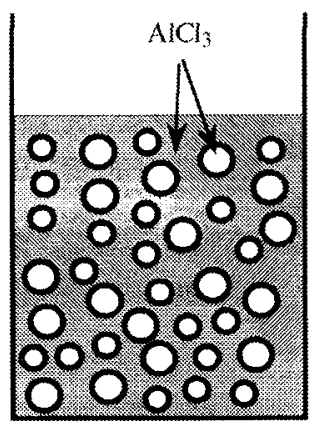

Single Compartment

Unilamellar Vesicles

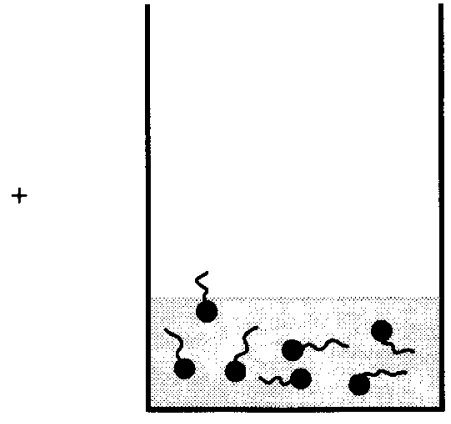

SDBS solution
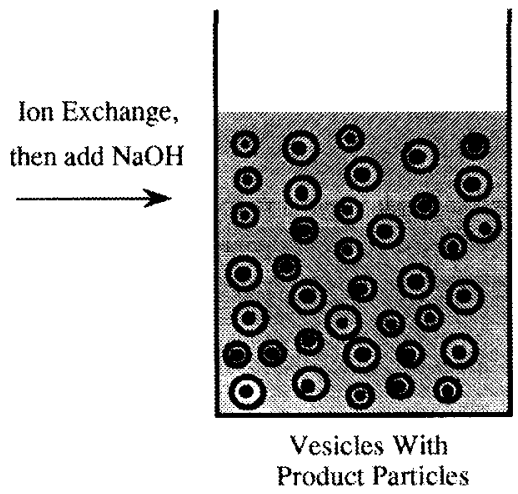

FIG. 1. Schematic illustration of the process used for intravesicular precipitation of aluminum hydroxide.

CTAT were prepared. $\mathrm{AlCl}_{3}$ was added to the CTAT to create a $0.7 \mathrm{M}$ salt solution. No electrolyte was added to the SDBS because the charge screening effect causes immediate precipitation of the surfactant. The CTAT and SDBS solutions were then mixed in a volume ratio of $8: 2$, creating a final $\mathrm{AlCl}_{3}$ concentration of approximately $0.6 \mathrm{M}$. In order for the precipitation to proceed, the vesicles must retain their integrity over the duration of the particle formation. Since the stability of the vesicles at these high salt concentrations had not been tested previously, the volume ratio was chosen so that the mixture retained a transparent bluish appearance for at least a few hours. Static light scattering measurements on these samples showed no change in absorption over several hours. QELS measurements showed a persistent single stable size distribution peak with a full width at half maximum of approximately $10 \%$, indicating the absence of any significant amounts of vesicle fusion or disintegration over the time period of the experiments. Visually, this solution appeared exactly like the suspension of spontaneous vesicles in water (which is known to be stable) for several hours. This solution was then passed through a column packed with sodium form ion exchange resin and the extravesicular $\mathrm{Al}^{+++}$concentration was reduced to less than $50 \mathrm{ppm}$, as indicated by a Quantofix ${ }^{\mathrm{TM}}$ test stick. $\mathrm{NaOH}$ was then added to the extravesicular solution until the 
$\mathrm{pH}$ reached 11.5 (this extravesicular $\mathrm{pH}$ was sustained by replenishing the external sodium hydroxide over time), initiating the intravesicular reaction.

Samples of the resulting solution were withdrawn $0.5,1$, and $2 \mathrm{~h}$ after the addition of $\mathrm{NaOH}$. Each sample was put on a carbon coated copper transmission electron microscope grid, the excess liquid blotted, then observed under a JEOL 1200EX scanning transmission electron microscope. Stage tilting was used to determine the morphology of the particles, and single particle as well as wide area electron diffraction patterns were obtained to determine their crystalline nature and identify their phase.

To complement the electron diffraction results, and to eliminate the possibility of electron beam heating effects creating artifacts in the identification of the phase of the particles, powder x-ray diffraction (Scintag XDS2000) was also used. To prepare the sample for this step, the vesicle membranes surrounding the particles were dissolved by adding Triton $\mathrm{X}-100,{ }^{13}$ and the solution was diluted to reduce the concentration of $\mathrm{NaCl}(\mathrm{NaCl}$ produces strong interference in the $\mathrm{x}$-ray diffraction). This solution was left for a few days allowing the particles to sediment (although Brownian motion would basically leave these particles stably suspended, lack of the surrounding membrane causes these particles to grow by Ostwald ripening and also agglomerate, permitting the larger entities to sediment). The upper aqueous phase was decanted; the particles in the lower phase were collected and dried on a microscope slide and then subjected to the $\mathrm{x}$-ray diffraction analysis.

\section{RESULTS AND DISCUSSION}

Figure 2 is a typical electron micrograph of product particles apparently surrounded by vesicles (absolute confirmation that vesicles are indeed surrounding the particles can be obtained only by doing cryo-TEM, but that is beyond the scope of this paper). Minimal variations in gray level were observed across each of these particles, indicating that they were essentially voidfree. Single particle electron diffraction, shown in Fig. 3, displays a pair of symmetric spots, indicating that these particles are either single crystals or have a low number of grain boundaries or defects. The $d$-spacings from wide area electron diffraction are shown in Table I, and produce a reasonable match with $\delta-\mathrm{Al}_{2} \mathrm{O}_{3}$. The stage tilting experiments revealed that these particles are spherical.

The overall kinetics of particle formation is followed by examining the particle size distribution at different time points after the addition of sodium hydroxide (the $\mathrm{pH}$ of the solution is maintained constant at 11.5), and is shown in Fig. 4. The sample size is 190 particles; while not being large enough to make firm quantitative

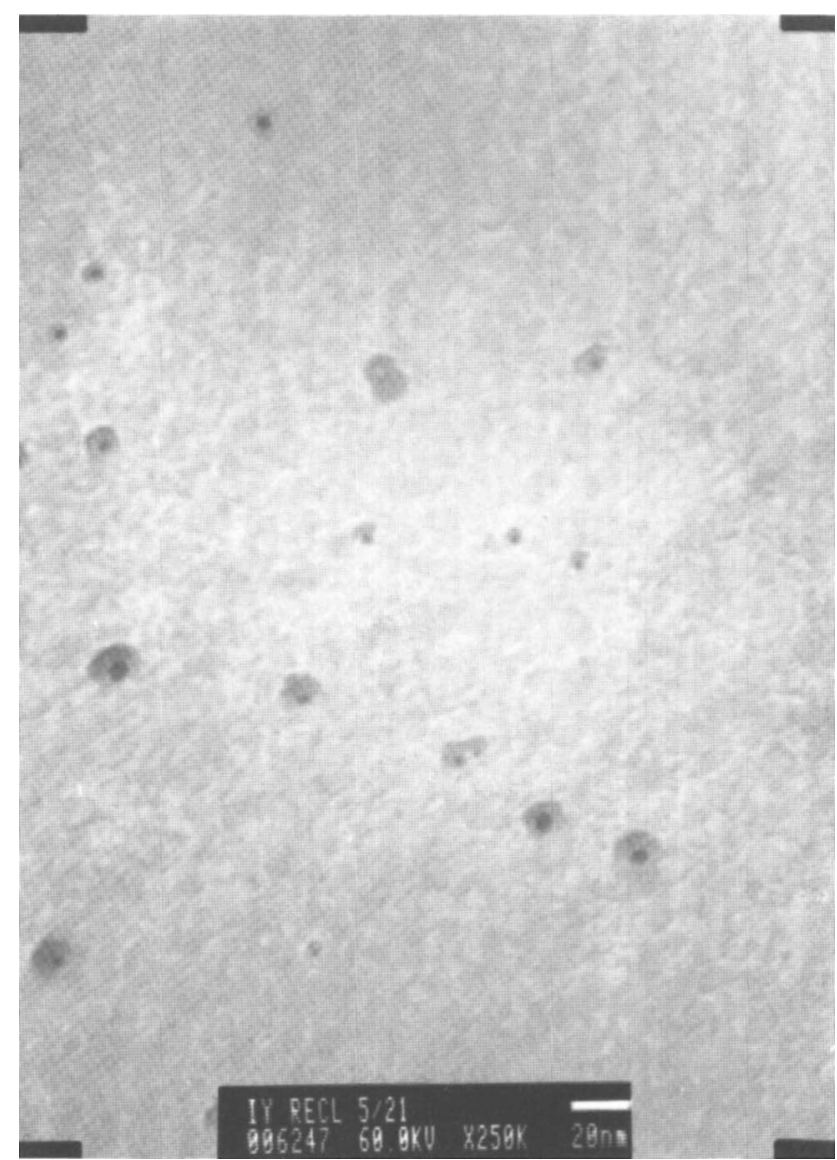

FIG. 2. Transmission electron micrograph of intravesicular product for the reaction of $\mathrm{AlCl}_{3}$ with $\mathrm{NaOH}$ in spontaneously formed vesicles using CTAT/SDBS surfactants.

conclusions, it is adequate to show trends in the data. Figure 4(a) is the size distribution of these particles $0.5 \mathrm{~h}$ after addition of $\mathrm{NaOH}$. The mean diameter of the particles is approximately $5.7 \mathrm{~nm}$. Figure 4(b) is the size distribution $1 \mathrm{~h}$ after the addition of $\mathrm{NaOH}$; the particles have grown to a mean diameter of about $7.3 \mathrm{~nm}$. Figure 4(c) shows the size distribution $2 \mathrm{~h}$ after the addition of $\mathrm{NaOH}$. The mean diameter remains unchanged, indicating the exhaustion of all intravesicular cations after $1 \mathrm{~h}$. Furthermore, this particle size distribution did not vary even at later time points, indicating that the vesicle membrane completely isolates the particles from the surroundings and prevents Ostwald ripening. If the initial aluminum salt concentration is reduced to $0.3 \mathrm{M}$, the mean particle diameter $1 \mathrm{~h}$ after addition of $\mathrm{NaOH}$ is $3.1 \mathrm{~nm}$, showing that particle sizes can be very effectively and easily controlled.

Figure 5 shows the $x$-ray diffraction pattern of the intravesicular product particles. Clearly the intravesicular phase is $\mathrm{Al}(\mathrm{OH})_{3}$ (bayerite), and not the $\delta$-alumina phase indicated by the wide area electron diffraction. 


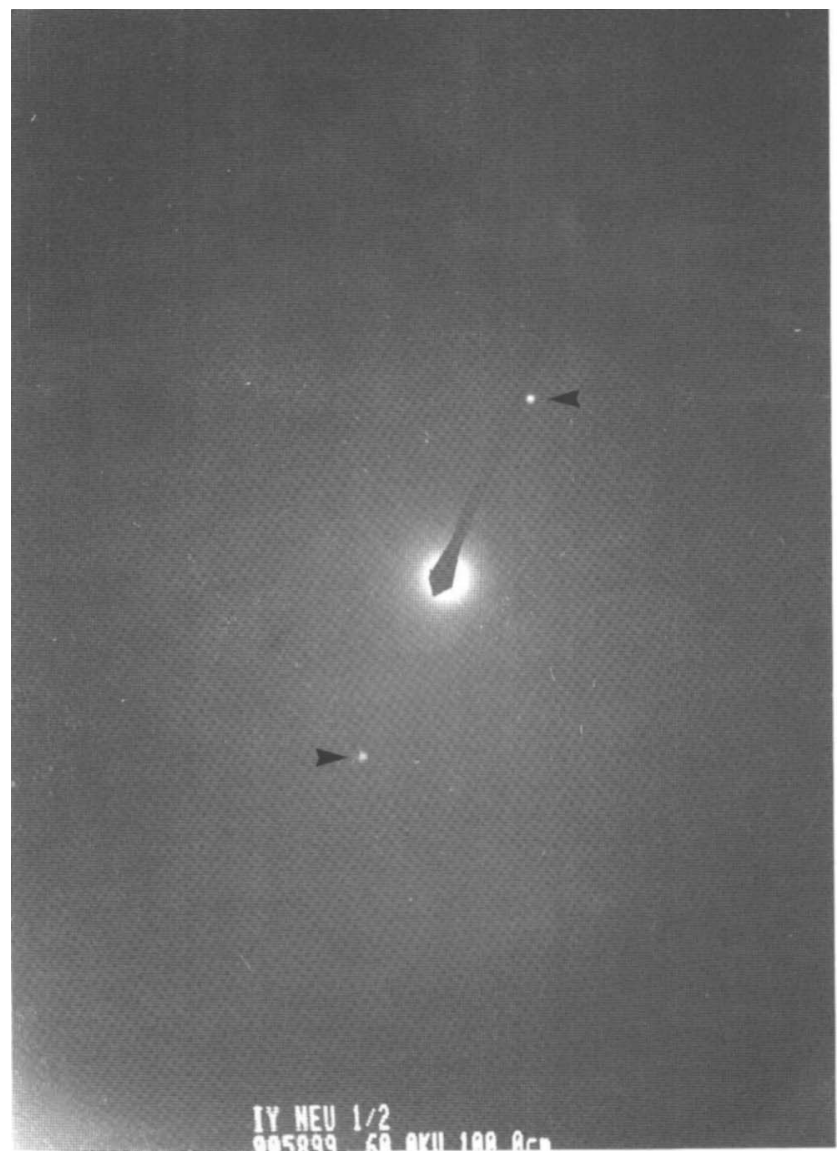

FIG. 3. Single particle electron diffraction of the reaction product. The pair of symmetric spots (see arrowheads) indicates that the product is either a single crystal or a particle with few grain boundarics or defects.

These results point dramatically to the artifacts caused by electron beam heating during phase identification of nanoparticles by electron diffraction.

TABLE I. $d$-spacings in $\AA$ for intravesicular product of $0.6 \mathrm{M} \mathrm{AlCl}_{3}$ with $0.5 \mathrm{M} \mathrm{NaOH}$ and comparison with ASTM x-ray diffraction data card for $\delta-\mathrm{Al}_{2} \mathrm{O}_{3}$ (intense peaks are underlined).

\begin{tabular}{cc}
\hline \hline Electron diffraction & X-ray data card \\
\hline 3.25 & $\ldots$ \\
$\ldots$ & 2.87 \\
$\underline{2.73}$ & $\frac{2.73}{2.58}$ \\
2.58 & $\frac{2.43}{2.28}$ \\
$\underline{2.42}$ & $\underline{1.99}$ \\
2.28 & 1.95 \\
$\underline{1.99}$ & 1.80 \\
$\ldots$ & 1.54 \\
1.79 & $\underline{1.39}$ \\
1.54 & 1.29 \\
$\underline{1.38}$ & 1.26 \\
1.24 & \\
\hline
\end{tabular}
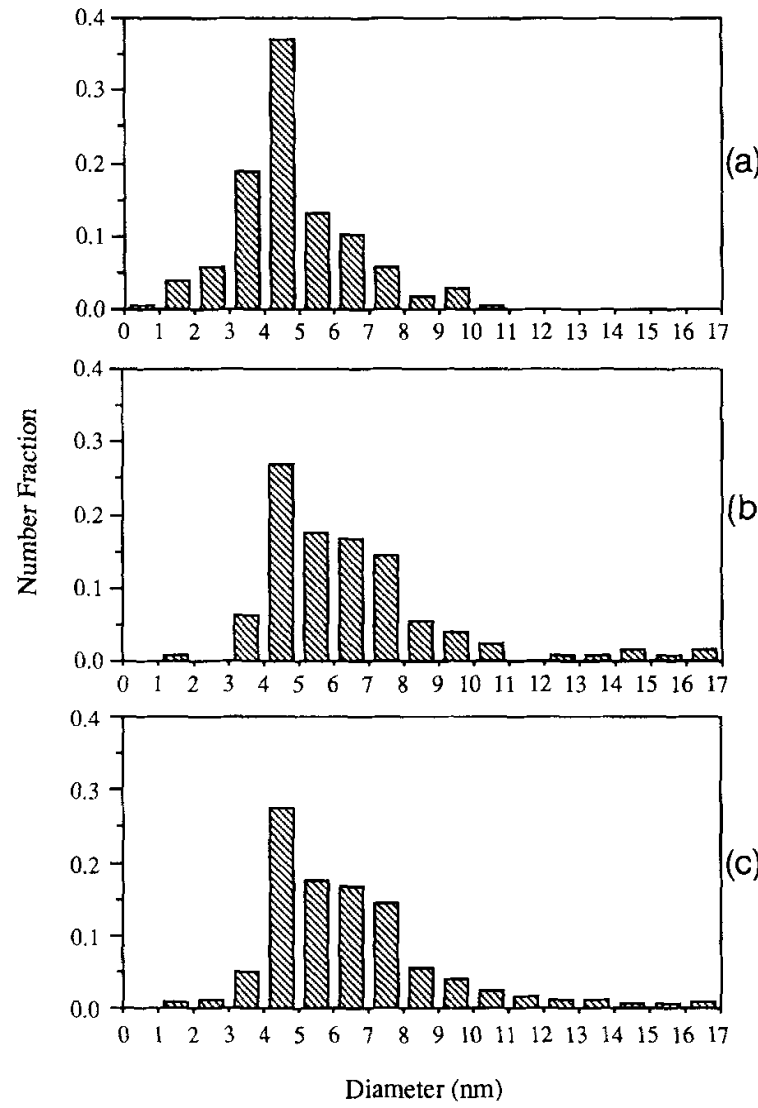

FIG. 4. Particle size distribution obtained at various time points after addition of $\mathrm{NaOH}$ to the extravesicular phase. The initial $\mathrm{AlCl}_{3}$ concentration is $0.6 \mathrm{M}$ : (a) $0.5 \mathrm{~h}$, (b) $1 \mathrm{~h}$, and (c) $2 \mathrm{~h}$.

It is worthwhile noting that the bulk phase reaction of $\mathrm{AlCl}_{3}$ with $\mathrm{NaOH}$ usually results in a gelatinous, $\mathrm{pH}$ dependent product. At present, we are unable to probe the intravesicular $\mathrm{pH}$ or aluminum ion concentration directly; nevertheless, the morphology of the product particles differs dramatically from that produced by free precipitation.

\section{CONCLUSIONS}

Spontaneous vesicles produced by mixing appropriate proportions of the single-tailed cationic and anionic surfactants (CTAT and SDBS) have been used as nanoreactors for synthesizing ultrafine spherical aluminum hydroxide particles. This procedure removes the energy intensive sonication step necessary for producing unilamellar vesicles from phospholipids, uses inexpensive and readily available raw materials, and allows the membrane surrounding the particles to be removed easily. Although we have reported only the results from a single aluminum salt in this paper, we have now demonstrated the viability of this technique for producing silver halide and iron oxide nanoparticles. ${ }^{14}$ 


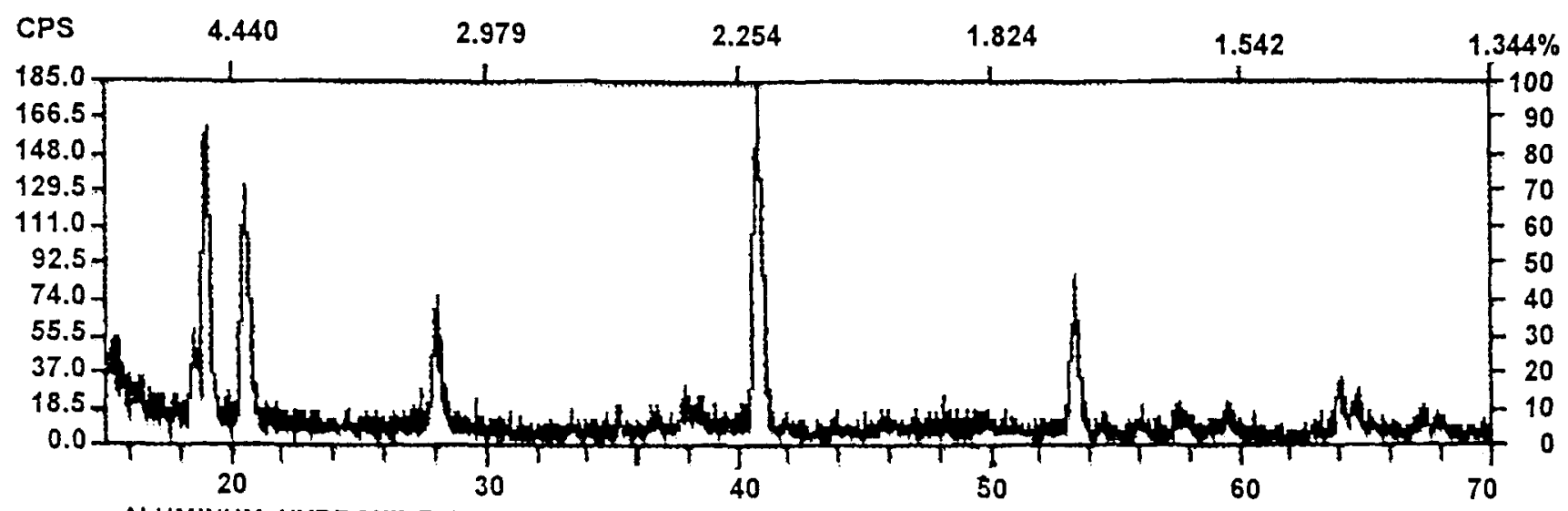

ALUMINUM HYDROXIDE / BAYERITE, SYN

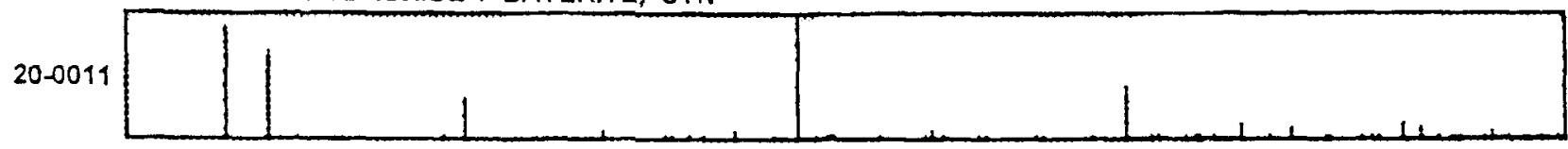

$\mathrm{AL}(\mathrm{OH})^{3}$

FIG. 5. X-ray diffraction pattern of intravesicular product.

\section{ACKNOWLEDGMENTS}

We thank E. Kaler, D. O. Shah, J. Estrin, and A.C. Nunes for several useful discussions, E. Arnold for helping us with the $\mathrm{x}$-ray diffractometer, P. W. Johnson for help in electron microscopy, and an anonymous reviewer for suggesting several clarifications. Financial support for this work was provided by the National Science Foundation (CBT 8803047 , CTS 8922574), the Eastman Kodak Company, and the ALCOA Foundation.

\section{REFERENCES}

1. C. R. Veale, Fine Powders: Preparation, Properties and Uses (Halsted Press Div., John Wiley \& Sons, Inc., New York, 1972).

2. J.S. Wey, J. Imag. Sci. 34, 202 (1990).

3. S. Mann and R.J.P. Williams, J. Chem. Soc. Dalton Trans., 311 (1983).

4. S. Mann and J. P. Hannington, J. Colloid Int. Sci. 122, 326 (1988).
5. S. Bhandarkar, I. Yaacob, and A. Bose, in Better Ceramics Through Chemistry IV, edited by B. J. J. Zelinski, C. J. Brinker, D. E. Clark, and D. R. Ulrich (Mater. Res. Soc. Symp. Proc. 180, Pittsburgh, PA, 1990), p. 637.

6. J. Karch, R. Birringer, and H. Gleiter, Nature 556, 330 (1987).

7. L. H. Edelson and A. M. Glaeser, J. Am. Ceram. Soc. 71, 225 (1988).

8. E. Matijević, in Ultrastructure Processing of Ceramics and Glasses, edited by L. L. Hench and D. R. Ulrich (John Wiley \& Sons, New York, 1984), p. 367.

9. R. W. Siegel, Mater. Res. Bull. XV, 60 (1990).

10. S. Bhandarkar and A. Bose, J. Colloid Int. Sci. 135, 531 (1990).

11. S. Bhandarkar and A. Bose, J. Colloid Int. Sci. 139, 541 (1990).

12. H. Liu, G. L. Graff, M. Hyde, M. Sarikaya, and I. A. Aksay, in Materials Synthesis Based on Biological Processes, edited by M. Alper, P.D. Calvert, R. Frankel, P.C. Rieke, and D. A. Tirrell (Mater. Res. Soc. Symp. Proc. 218, Pittsburgh, PA, 1991).

13. E. W. Kaler, A. K. Murthy, B. E. Rodriguez, and J. A. N. Zasadzinski, Science 245, 1371 (1989).

14. I. Yaacob, M.S. Thesis (University of Rhode Island, 1992). 